\title{
Ocular Ultrasonography and Biometry of Healthy Eyes in White Leghorn Birds
}

\author{
Ankur Sharma ${ }^{1 *}$, Shilpa Sood ${ }^{2}$, Priyanka Pandey ${ }^{1}$, H.R. Bhardwaj ${ }^{1}$, P. Gupta ${ }^{1}$, A. Kumar ${ }^{3}$, \\ D.K. Dwivedi ${ }^{1}$, D. Chakraborty ${ }^{4}$ and Satuti Sharma ${ }^{2}$ \\ ${ }^{1}$ Division of Veterinary Surgery and Radiology, Faculty of Veterinary Sciences and Animal Husbandry, SKUAST-J, \\ R.S. Pura, Jammu, JEK, INDIA \\ ${ }^{2}$ Division of Veterinary Pathology,Faculty of Veterinary Sciences and Animal Husbandry, SKUAST-J, R.S. Pura, \\ Jammu, JEK, INDIA \\ ${ }^{3}$ Division of Teaching Veterinary Clinical Complex, Faculty of Veterinary Sciences and Animal Husbandry, SKUAST-J, \\ RS Pura, Jammu, JEK, INDIA \\ ${ }^{4}$ Division of Animal Genetics and Breeding, Faculty of Veterinary Sciences and Animal Husbandry, SKUAST-J, R.S. Pura, \\ Jammu, JEK, INDIA \\ "Corresponding author: A Sharma; E-mail: ankurvets@gmail.com
}

Received: 10 June, 2021

Revised: 12 July, 2021

Accepted: 18 July, 2021

\begin{abstract}
Ocular ultrasonography is an important diagnostic tool which permits precise assessment of the eyeball and orbital structures contributing to a quick diagnosis and better therapy. The objective of the study was to describe the ultrasonographic appearance of the normal poultry eyes and to compare the biometric measurements of both the eyes. Hundred eyes from 50 poultry birds were assessed after a routine ophthalmic examination using an $10 \mathrm{MHZ}$ linear transducer. Ultrasound examination could clearly differentiate different parts of the internal eye, including the pecten oculi in the vitreous. Ocular biometry was performed by B-scan of the following structures (in mm): Corneal thickness (CT) (RE: 0.13 \pm 0.07 , LE: $0.12 \pm 0.07)$, Axial length (AL) (RE: $1.13 \pm 0.01$, LE: $1.05 \pm 0.18$ ), Lens width (LW) (RE: $0.33 \pm 0.15$, LE: $0.34 \pm 0.19$ ). Lens length (LL) (RE: $0.71 \pm 0.02$, LE: 0.65 \pm 0.02 ). There was a uniform correlation between the ocular structures, however, no statistical difference was observed in the parameters of both the eyes. The anatomic and biometric assessment will be helpful in identifying routine clinical abnormalities.

\section{HIGHLIGHTS}

( Study focused on ultrasonographic examination of poultry eyes.

( Ultrasound examination can easily differentiate different parts of the internal eye, including the pecten oculi in the vitreous.

(0 A uniform correlation between the ocular structures of both the eyes was seen.
\end{abstract}

Keywords: Biometry, Ocular, Ultrasonography, Poultry, White leghorn

Ophthalmology of mammalian domestic species is well established, however, there is a wide discrepancy regarding domestic and wild birds due to the large number of existing species (Carvalho et al., 2018). Eye disorders are not generally prevalent in poultry on a flock basis. However, sense of sight is necessary to carry out their daily activities and a higher incidence of ocular problems would result in decreased flock performance. A visually impaired bird is at a major disadvantage in competing for food, water, and social position in a population of birds (Jacob et al., 2008).
Ocular ultrasonography is an indispensable tool in veterinary ophthalmology as it is safe and non-invasive procedure that enables the evaluation of intraocular structures without the need to anaesthetise the patient. Ultrasonography is performed as a routine procedure in dogs

How to cite this article: Sharma, A., Sood, S., Pandey, P., Bhardwaj, H.R. Gupta, P., Kumar, A., Dwivedi, D.K., Chakraborty, D. and Sharma, S (2021). Ocular Ultrasonography and Biometry of Healthy Eyes in White Leghorn Birds. J. Anim. Res., 11(04): 733-736.

Source of Support: None; Conflict of Interest: None क्ष 
and cats, but rarely done for avian species (Gumpenberger and Kolm, 2005). A detailed ultrasonographic study was carried out on 100 eyes of 50 normal poultry birds; White leghorn (Gallus gallusdomesticus) aging one month old over a period of one year. The normal eye was scanned and biometric measurements of normal ocular structures were done. There are numerous features inherent to bird eye that make it essential to investigate and report reference values in them. Therefore, the present study was planned with the objective to describe the sonographic characteristics of the normal poultry eye and to compare its biometric measurements in both the eyes.

\section{MATERIALS AND METHODS}

All the presented 50 poultry birds underwent a thorough physical examination, followed by a routine ophthalmic examination of both the eyes (100) which included clinical examination of the ocular and peri-ocular areas followed by an ocular ultrasonography. Patients were positioned upright holding head in position using normal restraint techniques. Ultrasonography was performed after routine ophthalmic examination in 50 poultry birds. A drop of proparacaine $0.5 \%$ (Procaine eye drops, Search Orbis, Solan) was instilled on the corneal surface and Lignocaine jelly (Lox 2\% jelly, Neon Laboratories, Thane) was applied as a coupling gel directly to the globe. All ocular ultrasound examination was performed using 10 $\mathrm{MHz}$ linear transducer with a CHISONi8Vet ultrasound machine. The eyes were then scanned in B-mode by sagittal planes. No stand-off pad was used in any of the examined eyes. For standardization, the right eye was assessed first followed by the left eye. Physiological appearance of the ocular and peri-ocular structures were recorded and biometric measurements were obtained (in $\mathrm{mm}$ ). Thickness of the cornea (CT) was recorded as the distance between two corneal surfaces. Lens width (LW) was recorded as the distance between the anterior and posterior lens capsule, Lens length (LL) was observed as the distance between the side and mid-poles of the lens. Axial length of eye (AL) was observed to be the distance between the central point of cornea to the internal face of retina-choroid-sclera complex. All measurements were performed by a single investigator to minimize chances of errors in biometry assessment and positioning. Statistical analysis was done using SPSS software V.16. Comparative measurements of both contralateral eyes (right and left) were done using student's ' $\mathrm{t}$ ' test where $\mathrm{p}$ values $<0.05$ were considered significant.

\section{RESULTS AND DISCUSSION}

Ultrasound examination proved to be a quick noninvasive imaging technique permitting the identification, assessment and measurement of all the components of the eyeball without any iatrogenic injury to the corneal surface as also demonstrated by Gumpenberger and Kolm, 2006 who also observed that ocular disorders within the anterior chamber and vitreous became more obvious using ultrasound. However, Penha et al. (2012) have observed a high correlation between ocular biometry using A-scan ultrasonography and optical low-coherence interferometry (OLCI) in the anesthetized chicken with higher lateral and axial resolution in chicken eye. All the cases employed Proparacaine $\mathrm{HCl},(0.5 \%)$ as a corneal anaesthetic and no other agents were used in this study or deemed necessary as all the birds were cooperative and allowed the examination. The bird was hand-held and the open end of the tube was placed on the corneal surface near the optic axis. Prior research on chick eyes has shown that when both the eyes receive the same treatment, the results in both eyes are virtually identical, which was also confirmed by Li and Howland, (2006), however, they measured data from only one right eye whereas both eyes have been studied in the present study.

Globular shape of bulbus was seen on ultrasound examination. The cornea was characterised by curvilinear hyper-echogenic margins (Fig. 1a). The anterior chamber was anechoic without any floating contents in the aqueous humor. The lens consisted of two curvilinear hyperechoic lines with an anechoic center. Reverberation artifacts of moderate echogenicity were sometimes seen over the cornea. The ciliary body of moderate echogenicity was also observed on both sides of the lens. It has been reported that ocular and lenticular biometry can change with age (Irribarren et al. 2014). The vitreous body appeared anechoic with moderately echogenic visible pecten oculi, which was adequate for its examination. Pecten is a vascular and pigmented structure, which was localized within the posterior segment of all avian eyes (Ferreira et al., 2018). In all the cases, it caused slight to moderate shadowing and it is reported that ultrasound is the only imaging tool that is able to diagnose pecten anomalies in 

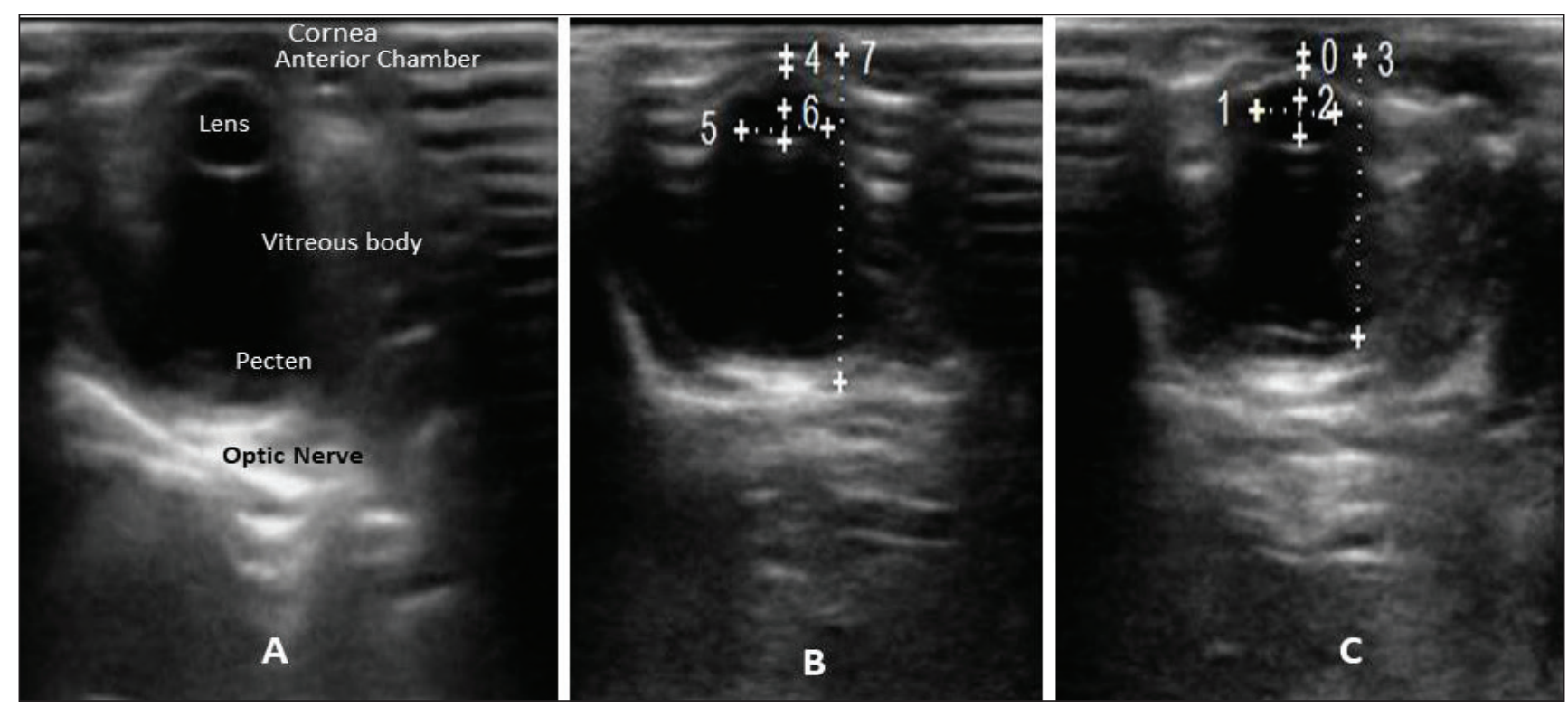

Fig. 1: Ocular ultrasonography of white leghorn birds (Gallus gallusdomesticus). (A) Ultrasonographic appearance of eye. (B) Biometry of ocular structures of right; (C) left eye Corneal thickness (CT), Lens width (LW), Lens length (LL) and Axial length (AL)

birds as also observed by Peschel et al. (2018). However, on ultrasound examination, margins of pecten oculi were indistinct. The retina, choroid and sclera were difficult to differentiate and appeared as hyperechoic lines in the posterior globe wall. Retrobulbar fat and other tissues could not be easily distinguished from the posterior wall of the globe. It has been observed that the usefulness of ultrasound is limited to the evaluation of the orbit, optic nerve, and fibrous tunics due to the distal shadowing and artifacts caused by scleral ossicles as has been observed by Gumpenberger and Kolm, (2006) also. Hyperechoic retrobulbar tissue was identified as the optic nerve. A favourable relationship between the corneal thickness, lens, and axial length of the eye could be measured with the help of ultrasound.

Hamidzada and Osuobeni (1999) recommended the use of B-mode ultrasound as it was technically easier to use, however, B-mode may overestimate corneal thickness, and anterior chamber depth and thickness of lens, vitreous chamber depth and axial length could be underestimated. This was also observed in few cases of the study, where thickness of the cornea was difficult to differentiate.

The biometric measurements of the eyeball are presented in Fig. 1B,C, Table 1 and Fig. 2. Comparative assessment of the ocular structures between the right and left eye showed bilateral symmetry and there were no significant statistical difference between both the eyes.

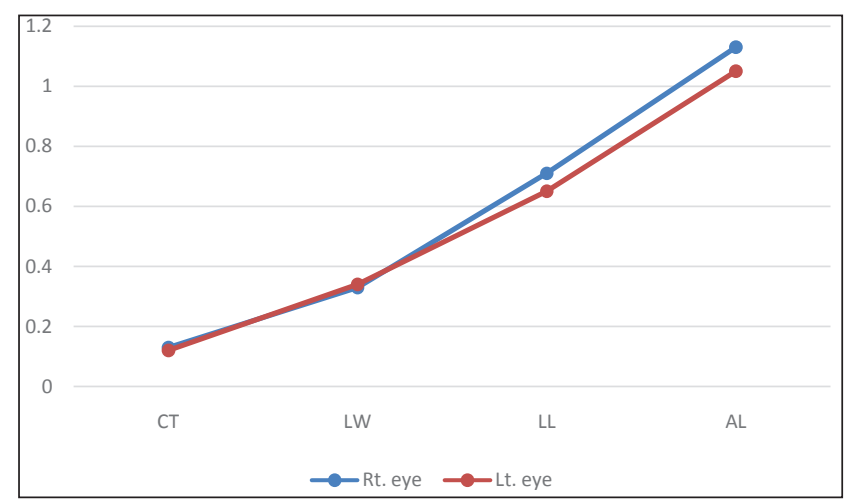

Fig. 2: Ocular biometry of normal structures of both the eyes. (CT-Corneal Thickness, LW- Lens width, LL-Lens length, ALAxial Length)

Table 1: Biometry of ocular structures in 100 eyes of 50 White leghorn birds (in mm)

\begin{tabular}{|c|c|c|c|c|}
\hline Eye & $\begin{array}{l}\text { Corneal } \\
\text { thickness (CT) }\end{array}$ & $\begin{array}{l}\text { Lens thickness } \\
\text { (LW) }\end{array}$ & $\begin{array}{l}\text { Lens length } \\
\text { (LL) }\end{array}$ & $\begin{array}{l}\text { Axial length } \\
\text { (AL) }\end{array}$ \\
\hline $\mathrm{RE}$ & $0.13 \pm 0.007^{b}$ & $0.33 \pm 0.015^{\mathrm{a}}$ & $0.71 \pm 0.020^{\mathrm{b}}$ & $1.13 \pm 0.01^{\mathrm{b}}$ \\
\hline LE & $0.12 \pm 0.007^{\mathrm{a}}$ & $0.34 \pm 0.019^{b}$ & $0.65 \pm 0.024^{\mathrm{a}}$ & $1.05 \pm 0.18^{\mathrm{a}}$ \\
\hline
\end{tabular}


Corneal thickness (CT) of right and left eyes was 0.13 \pm 0.07 and $0.12 \pm 0.07$ respectively. In two-dimensional mode biometry, cornea is flattened by the transducer, leading to a depth of $0.14 \mathrm{~cm}$ as also observed by Goncalves et al. (2000); Silva et al. (2018) who observed less resolution power of low frequency transducer as the cause for flattening phenomenon. Resolution power was not reduced inspite of not using the standoff pad, as gel provided a thick layer between transducer and cornea providing complete analysis. All the measurements were obtained by a single investigator, which favoured biometric assessment that is in agreement with Findl et al. (2003) and Silva et al. (2018).

The means of lens thickness (in $\mathrm{mm}$ ) were $0.33 \pm 0.15$ for right eye and $0.34 \pm 0.19$ for left eye and length of lens was $0.71 \pm 0.02$ (right eye) and $0.65 \pm 0.02$ (left eye). The axial length of the right and left eyes were $1.13 \pm 0.01$ and $1.05 \pm 0.01$ ) respectively which did not vary much between the both the eyes. It has been reported by Mutti et al. (2005) and Iribarren et al. (2014), that during the first three months of chicken growth, corneal power reduces, while axial length and lens power steadily change, these variations have also been reported after birth in nonhuman primates.

\section{CONCLUSION}

Ocular ultrasound using B mode, is suitable for routine use in birds, providing precise assessment and measurement of the eyeball structures. It is advantageous to examine the internal ocular structures especially when the cornea is damaged or there are opacities.

\section{REFERENCES}

Carvalho, C.M., Rodarte-Almeida, A.C., Santana, M.I.C. and Galera, P.D. 2018. Avian ophthalmic peculiarities. Ciencia. Rural, 48: 12.

Ferreira, T.A.C., Fornazari, G., Saldanha, A., Lunardeli, B., Moore, B.A. and Ferreira, F.M. 2018. The use of sulfur hexafluoride microbubble for contrast-enhances ocular ultrasonography of the pecten oculi in birds. Vet. Ophthalmol., pp. 1-7.
Findl, O., Kriechbaum, K., Sacu, S., Kiss, B., Polak, K., Nepp, J., Schild, G., Rainer, G., Maca, S., Petternel, V., Lackner, B. and Drexel, W. 2003. Influence of operator experience on the performance of ultrasound biometry compared to optical biometry before cataracta surgery. J. Cataract Refract. Surg., 29(10): 1950-1955.

Goncalves, G.F., Pippi, N.L., Raiser, A.G., Mazzanti, A., Oliveira, S.T., Neves, J.P., Leotte, A.M. and Hintz, C.W. 2000. Biometria ultra-sonographica bidimensional em tempo real do globo ocular de caes. Cienca Rural, 30(3): 417-420.

Gumpenberger, M. and Kolm, G. 2005. Ultrasonographic and computed tomographic examinations of the avian eye: physiologic appearance, pathologic findings, and comparative biometric measurement. Vet. Radiol. Ultrasound, 47(5): 492502 .

Hamidzada, W.A. and Osuobeni, E.P. 1999. Agreement between A-mode and B-mode ultrasonography in the measurement of ocular distances. Vet. Radiol. Ultrasound. 40: 502-507.

Irribaren, R., Rozema, J.J., Schaeffel, F. and Morgan, I.G. 2014. Calculation of crystalline lens power in chickens with a customized version of Bennett's equation, Vision Res., 96: 33-38.

Jacob, P., Butcher, G.D. and Mather, M.D. 2008. Eye Disorders of Poultry. Mather - Institute of Food and Agricultural Sciences, University of Florida.

Li, T. and Howland, H.C. 2006. Role of the Pineal Gland in Ocular Development of the Chick in Normal and Constant Light Conditions. Invest. Ophthal Visual Sci., 47: 5132-5136.

Penha, A.M., Burkhardt, E., Schaeffel, F. and Feldkaemper, M.P. 2012. Ultrasonography and optical low-coherence interferometry compared in the chicken eye. Optom Visual Science, 89(6): 916-21.

Peschel, A., Moser, K. and Korbel, R. 2018. Three-dimensional ultrasonographic examination of the avian eye: technique and physiological findings. Tierarztliche Praxis, 46(4): 236-245.

Silva, E.G., Pessoa, G.T., Laecio, S.M., Guerra, P.C., Rodrigues, R.P.S., Sousa, F.C.A., Ambrosio, C.E. and Alves, F.R. 2018. Biometric, B-mode and color dopppler ultrasound assessment of eyes in healthy dogs. Pesq. Vet. Bras., 38(3): 567-571. 